\title{
Obituary
}

\section{Professor HUANG Sheng-Kai}

\author{
Yi-zhong HU, Ling GAO
}

Acta Pharmacologica Sinica (2016) 37: 1645; doi: 10.1038/aps.2016.132

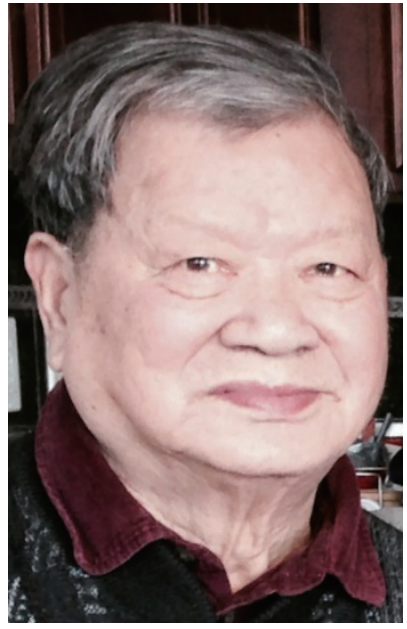

A former professor of China Pharmaceutical University and founder of Pharmacokinetics in China, passed away peacefully on October 5, 2016 at the age of 88 in the United States.

Professor HUANG Sheng-Kai was born on October 28, 1928 in Ningbo, Zhejiang Province in a family of pharmaceutical business. When he was young, Professor Huang's academic work was excellent. He was admitted to the Department of Pharmacy, Shanghai Medical University in 1948. After graduation in 1952, he was offered a position by Northeast Pharmaceutical Manufactory and worked as a scientist there. In 1954, he moved to Nanjing Pharmaceutical College (now China Pharmaceutical University) to pursue his academic interests. He started his academic career at the Department of Biochemistry, and switched to the Department of Pharmacology in 1984, where he focused on his teaching and research interest in Pharmacokinetics till his retirement in 1996.
When Pharmacokinetics was first established as an independent subject abroad in the late 1970s, Professor Huang worked diligently with Professor CHEN Gang from Nanjing Military Region General Hospital on writing the textbook of Pharmacokinetics in Chinese. The first Chinese version of "Pharmacokinetics" textbook was published in 1984. Since then, he dedicated the rest of his life to the education, development and application of Pharmacokinetics in China. He established a systematical education program on the theory and research methodologies of Pharmacokinetics. He also provided countless training courses and lectures to both academic institutions and pharmaceutical industries across the country. His effort and dedication greatly promoted the popularization and development of Pharmacokinetics in China. Moreover, he made great achievements in pharmacokinetic model theory, mathematical modeling and data processing through his own research labs. As an academic professor, he paid great attention to personnel training by taking the lead to introduce the pharmacokinetic courses to undergraduate and graduate students in China Pharmaceutical University. Professor Huang began to enroll graduate students in Pharmacokinetics in 1984 till 1993. His research area covered almost all aspects of Pharmacokinetics and brought up many talents in Pharmacokinetic field. Professor Huang led the establishment of first edition of Bioavailability-Bioequivalence guidance in China. He served as a member of the Drug Evaluation Committee of the Ministry of Public Health, member of the Chinese Pharmacological Society, member of the Experts Committee of the National Research and Development of New Drugs, Director of the Center for Pharmacokinetics and Drug Metabolism Research of the State Pharmaceutical Administration and had made immortal contribution to the subject of Pharmacokinetics in China.

Professor Huang's vibrant spirit will be missed by his family, friends, colleagues, and students forever. 